\title{
Animal Models of Kennedy Disease
}

\author{
Diane E. Merry \\ Department of Biochemistry and Molecular Pharmacology, Thomas Jefferson University, Philadelphia, Pennsylvania 19107
}

\begin{abstract}
Summary: Since the identification of the polyglutamine repeat expansion responsible for Kennedy disease (KD) more than a decade ago, several laboratories have created animal models for $\mathrm{KD}$. The slowly progressive nature of $\mathrm{KD}$, its $\mathrm{X}$-linked dominant mode of inheritance, and its recently elucidated hormone dependence have made the modeling of this lower motor neuron disease uniquely challenging. Several models have been generated in which variations in specificity, age of onset, and rate of progression have been achieved. Animal models that precisely reproduce the motor neuron specificity, delayed onset, and slow progression of disease may not support preclinical
\end{abstract}

therapeutics testing, whereas models with rapidly progressing symptoms may preclude the ability to fully elucidate pathogenic pathways. Drosophila models of $\mathrm{KD}$ provide unique opportunities to use the power of genetics to identify pathogenic pathways at work in KD. This paper reviews the new wealth of transgenic mouse and Drosophila models for KD. Whereas differences, primarily in neuropathological findings, exist in these models, these differences may be exploited to begin to elucidate the most relevant pathological features of KD. Key Words: Kennedy disease, polyglutamine, spinal and bulbar muscular atrophy, androgen receptor.

\section{KENNEDY DISEASE: SYMPTOMS, MOLECULAR GENETIC BASIS, AND PATHOLOGICAL FEATURES}

As with virtually all human neurodegenerative diseases, developing animal models of Kennedy disease (KD) has presented several challenges. The obstacles encountered have been both common to other neurodegenerative diseases and unique. Many of the common challenges will be found in other reviews on this topic; in brief, they include 1) the limited life span of an animal coupled with what is generally a slow degenerative process in adult KD patients, ${ }^{1}$ 2) maintaining specificity of disease while reproducing the precise mechanistic pathogenic process, and 3) creating a model in which disease onset and progression occur in a time course amenable to preclinical drug testing. A review of animal models for many neurodegenerative diseases quickly reveals that these many goals can rarely be achieved with a single model. In few diseases is this so clearly exemplified as with $\mathrm{KD}$.

One of the greatest challenges in modeling KD is the slowly progressing nature of the disease. KD typically strikes men during the fourth to fifth decade of life with

Address correspondence and reprint requests to Diane E. Merry, 208 Bluemle Life Sciences Building, 233 South 10th Street, Philadelphia, PA 19107. E-mail: diane.merry@jefferson.edu. weakness and atrophy of the proximal limb muscles and the bulbar muscles of the face and jaw. ${ }^{1}$ Fasciculations are a common feature of the disease and are most prominently seen on the tongue. While frank signs of muscle weakness and atrophy are typically not observed until mid-life, patients will often describe muscle cramping beginning decades earlier. Signs of upper motor neuron disease such as spasticity and hyperreflexia are absent from KD patients.

$\mathrm{KD}$ is a highly variable disease in its presentation. Whereas some patients may present with proximal limb weakness, others may suffer difficulties with speech and swallowing for years before signs of muscle weakness become apparent. Many KD patients use aids for ambulation; the most severely affected are wheelchair-bound, whereas others ambulate with little aid until quite late in life. The relative sparing of the diaphragm muscles allows KD patients to escape the devastating respiratory problems seen in amyotrophic lateral sclerosis (ALS). $\mathrm{KD}$ patients most frequently succumb to aspiration pneumonia, as a complication of bulbar muscle weakness and atrophy.

Pathologically, KD is characterized by the loss of motor neurons from the anterior horn of the spinal cord and from the brainstem. ${ }^{2}$ Remaining motor neurons may contain characteristic nuclear protein aggregates referred to as neuronal intranuclear inclusions (NII). ${ }^{3}$ These are found primarily in motor neurons of affected regions but 
may also be found at reduced frequency in other neuronal and nonneuronal populations. ${ }^{3,4}$ More recent data indicate that both the nuclear and cytoplasmic accumulation of mutant androgen receptor (AR), rather than NII, correlates with CAG repeat length in KD. Moreover, diffuse AR accumulation is more widespread, both within the nervous system and in peripheral tissues, than previously believed. ${ }^{3-5}$ Muscle pathology ${ }^{2}$ primarily reflects a process of neurogenic atrophy and includes the grouping of fiber types and the atrophy of grouped fiber types. Large areas of "bagged nuclei" are sometimes seen, reflecting atrophy of a single multinucleated fiber. Central nuclei are also observed.

The KD phenotype and mode of inheritance were first described in $1968 .{ }^{1}$ This slowly progressing lower motor neuron disease shows X-linked inheritance; males are affected, whereas females rarely exhibit symptoms of disease. In families in which symptoms have been described in heterozygous female carriers, these have occurred relatively late in life and with decreased severity. ${ }^{6}$ The KD gene was ultimately mapped to the proximal long arm of the $\mathrm{X}$ chromosome, to a region containing the AR gene. ${ }^{7,8}$ In 1991, a novel type of mutation was identified in the androgen receptor gene in KD patients, consisting of a moderately expanded trinucleotide (CAG) repeat within the first coding exon of the gene. ${ }^{9}$ The repeat encodes a polyglutamine tract, which is expressed within the mutant protein. To date, nine inherited neurodegenerative diseases occur due to the modest expansion of coding CAG repeats. In nearly all of these diseases, the CAG repeat is similar in its normal and disease expansion ranges, and in the finding that there exists an inverse correlation between repeat length and age of disease onset. ${ }^{10}$ Although similarities exist regarding the genetic basis of disease and the pathological manifestation of expanded polyglutamine, each disease affects distinct, albeit somewhat overlapping populations of neurons. ${ }^{11}$

\section{THE FIRST ANIMAL MODELS OF KD}

Unlike inherited neurologic diseases resulting from loss of gene function, dominantly inherited, progressive neurodegenerative diseases that manifest symptoms through the acquisition of a toxic protein property likely require the time-dependent accumulation of cellular insults to produce neuronal dysfunction and, ultimately, neuronal death. Such an understanding came from early attempts to model KD in transgenic mice. ${ }^{12-14}$ These attempts used both neuron-specific and nonspecific promoters, as well as that of the AR itself. In all three early studies designed to produce a mouse model of disease, no neurological phenotypes were observed in mice up to 2 years of age. Of note, however, was the finding that some transgenes used did not produce detectable mutant
AR protein in the target tissues of interest. ${ }^{12,14}$ Nonetheless, these models revealed important aspects of the genetic determinants of trinucleotide repeat instability. Bingham et al. ${ }^{12}$ produced several transgenic lines, using the interferon-inducible antiviral $\mathrm{Mx}$ promoter and the neuron-specific enolase promoter to drive the human androgen receptor cDNA carrying 44 repeats, a common repeat length in affected KD patients. These mice showed neither neurologic phenotypes nor the characteristic repeat instability found in KD families. On the other hand, transgenic mice created with a human mutant ARcontaining yeast artificial chromosome (YAC) ${ }^{14}$ exhibited repeat instability, despite the fact that they did not express the mutant protein at detectable levels and showed no neurological deficits. Thus, these mice were useful for determining cis-acting elements that contributed to the repeat instability phenotype.

Whereas the described transgenic models failed to reproduce the human neurological symptoms of KD due to the lack of suitable transgene expression, other mice failed to demonstrate a phenotype despite relatively high levels of protein expression. ${ }^{13}$ These mice used both neurofilament light chain (NF-L) and neuron-specific enolase (NSE) promoters to drive expression of a human cDNA carrying 65 CAG repeats. The inverse correlation between repeat length and age of onset in KD patients led to the idea that, whereas disease did not develop in mice bearing a 45-CAG transgene, perhaps it would develop in mice bearing a transgene containing the longest CAG repeat found in KD patients. Despite expression levels that reached two to five times endogenous AR levels, no neurological or behavioral abnormalities were observed in these transgenic mice, up to 2 years of age. Moreover, no pathological findings were seen. Therefore, despite the high expression of mutant AR protein in the appropriate target tissues and a CAG repeat length at the extreme of lengths found in KD patients, no disease developed. One interpretation of these data proposes that the dominant toxic property of the expanded polyglutamine protein requires a protracted time period for its development. Alternatively, the time that it takes for neurons to accumulate damage from the ever-present toxic species occurs over the course of years or decades. In either scenario, years are required for target neurons to develop phenotype-producing damage. Indeed, in the case of $\mathrm{KD}$, this time course is even more protracted than that for other polyglutamine diseases such as Huntington's disease. Moreover, whereas the aging process occurs in a mouse over the course of approximately 2 years, it is unclear whether the cellular processes that lead to either the accumulation of the toxic polyglutamine intermediate or the accumulation of cellular damage can occur in a population of mouse neurons in the course of 2 years. The experience gained from early transgenic mouse models, coupled with the knowledge of the in- 


\begin{tabular}{|c|c|c|c|c|}
\hline $\mathbf{A} / \mathbf{B}$ & C & D & E & F \\
\hline
\end{tabular}

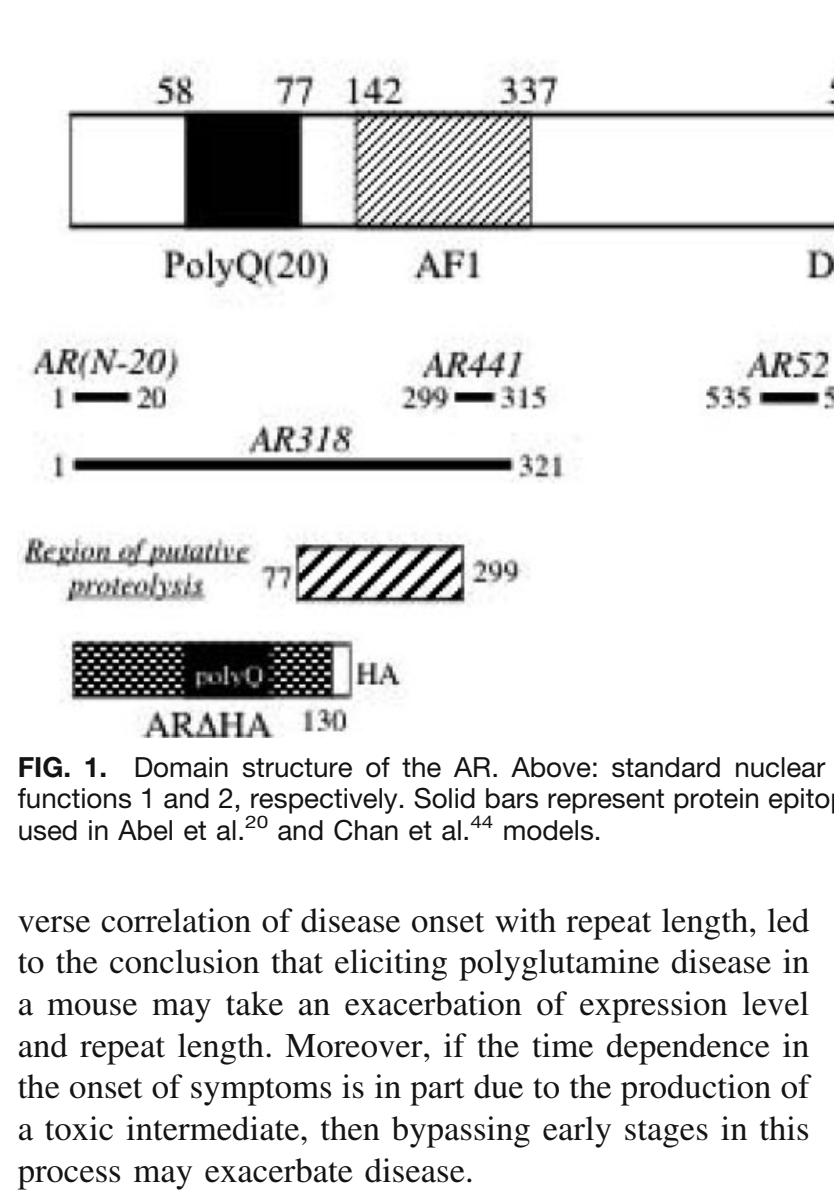

\section{THE TOXIC FRAGMENT (INTERMEDIATE) HYPOTHESIS}

The idea that toxicity of expanded polyglutamine proteins may be mediated by a fragment generated by proteolysis of the full-length mutant protein is supported by several observations. In $\mathrm{KD}$, the primary observation leading to this idea is that the NII found in disease autopsy material contain protein epitopes representing only a portion of the mutant protein. Specifically, NII in $\mathrm{KD}$ are immunoreactive for AR amino-terminal epitopes [detected with antibodies AR(N-20) and AR318], whereas both AR carboxyl-terminal and internal epitopes [detected with antibodies AR441, AR52, AR(C-19)] are absent $^{3,4}$ (FIG. 1). In addition, early molecular genetic studies in cell culture revealed that truncated polyglutamine species of another polyglutamine protein, ataxin-3, were more toxic than the full-length forms. ${ }^{15-19}$ In studies of KD, the expression of truncated, expanded AR species (FIG. 1) caused notable aggregation pathology, whereas that of full-length species did not. ${ }^{17-19}$

These experimental observations supported the notion that a truncated polyglutamine-containing AR species confers greater toxicity than the full-length form, and may represent a naturally occurring pathologic intermediate. Indeed, transgenic mouse models in which a truncated form of expanded AR (FIG. 1) was expressed demonstrated substantial neurologic dysfunction. ${ }^{20}$ The truncated species in these studies represented a fragment estimated to be similar to that found in NII, and known to freely aggregate. ${ }^{17,19}$ Moreover, the repeat length used (112) was substantially longer than that previously used, based on the knowledge of the inverse correlation of repeat length with age of disease onset. ${ }^{10}$

Transgenic mice created with this truncated construct (tAR) (Table 1) developed phenotypes dependent on the promoter used. ${ }^{20}$ Whereas strong and widespread expression via the prion protein $(\mathrm{PrP})$ promoter resulted in early and severe neurologic symptoms, the more limited expression driven by the NF-L promoter resulted in a focused motor dysfunction beginning much later, at approximately 8 months of age. PrP-tAR112 mice exhibited increased grooming, resting tremor, gait abnormalities and handling-induced seizures by 6-8 weeks of age. Death occurred shortly thereafter. In keeping with the extensive neurologic deficits, the pathological formation of NII was observed in all neurons of the brain and spinal cord. In contrast, transgenic mice expressing the same truncated AR species via the NF-L promoter displayed no neurological deficits until 8 months of age. At that time, mice developed severe spastic gait abnormalities and hindlimb weakness; death ensued within 6 months.

Neither of these transgenic mouse models ${ }^{20}$ reproduced the lower motor neuron specificity of KD, al- 
TABLE 1. KD Animal Models with Phenotype

\begin{tabular}{|c|c|c|c|c|c|}
\hline & $\begin{array}{c}\text { Full-Length (FL) } \\
\text { or Truncated } \\
(\mathrm{Tr})\end{array}$ & $\begin{array}{c}\text { NII } \\
\text { Present }\end{array}$ & $\begin{array}{l}\text { Neuronal } \\
\text { Cell Death }\end{array}$ & $\begin{array}{c}\text { Muscle } \\
\text { Pathology }\end{array}$ & $\begin{array}{c}\text { Gender Differences/ } \\
\text { Hormone Effect }\end{array}$ \\
\hline \multicolumn{6}{|c|}{ Full-Length Transgenic Mouse Models } \\
\hline Katsuno et al., $2002^{23}$ & FL & Yes & No & Yes & Yes \\
\hline McManammy et al., $2002^{22}$ & FL & No & Yes & Yes & Mild \\
\hline Chevalier-Larsen et al., $2004^{25}$ & FL & Yes & No & No & Yes \\
\hline Sopher et al., $2004^{24}$ & FL & No & Yes & Yes & Yes \\
\hline \multicolumn{6}{|c|}{ Truncated Transgenic Mouse Models } \\
\hline Abel et al., 200120 & $\operatorname{Tr}$ & Yes & No & No & No \\
\hline Adachi et al., $2001^{21}$ & PolyQ & Yes & No & No & No \\
\hline \multicolumn{6}{|l|}{ Drosophila Models } \\
\hline Chan et al., $2001^{44}$ & $\operatorname{Tr}$ & Yes & Yes & NA & No \\
\hline Takeyama et al., $2001^{45}$ & FL & Yes & Yes & NA & Yes \\
\hline
\end{tabular}

though NF-L-tAR112 mice developed hindlimb gait abnormalities and weakness. However, the abnormal gait showed substantial spasticity, a feature of upper motor neuron disease found in ALS but not KD. Neither model reproduced the male gender specificity of $\mathrm{KD}$, suggesting that the protein region responsible for gender specificity was absent from the transgene. Indeed, the transgene lacked both the hormone-binding and DNA-binding domains of the AR. These results showed that, whereas a truncated, expanded fragment of the AR is capable of causing progressive neurologic disease, such a fragment lacks the components required to confer both the neuronal cell type and gender specificity that characterize KD.

A similar transgenic mouse model was described shortly thereafter by Adachi et al. ${ }^{21}$ This model used the AR promoter to drive expression of a very long polyglutamine tract (239 residues), rather than the AR protein itself. This complementary approach produced mice with neurological deficits that included ataxia and muscle weakness, as well as early death. Therefore, despite targeting expanded polyglutamine expression to neurons in which the AR was normally expressed, this transgenic model also failed to reproduce the motor neuron and gender specificity of KD. These data suggest that expression patterns alone are likely insufficient to confer motor neuron specificity.

An important result of the studies described by Abel et al. ${ }^{20}$ and Adachi et al. ${ }^{21}$ was the finding that mice developed severe neurologic disease and early death in the absence of notable neuronal loss. That the lack of neuronal degeneration was observed in mice with ages at death ranging from 6-8 weeks for PrP transgenic mice ${ }^{20}$ to 3-5 months for AR-239Q transgenic mice ${ }^{21}$ to 14 months for NF-L transgenic mice ${ }^{20}$ suggests that, regardless of the rapidity of death, neurologic symptoms are consistently observed in the absence of neuronal cell death. The question of whether cell death represents a feature of full-length mutant AR pathology would be tested by full-length AR models.

\section{A ROLE FOR HORMONE IN KD}

The finding that transgenic mouse models consisting of either a truncated AR expressed from heterologous promoters or an isolated polyglutamine tract expressed from the AR promoter failed to model motor neuron and gender specificity indicated that these characteristics likely require expression of the full-length AR protein. In addition, the important question of the role of hormone binding in the pathogenesis of disease requires models in which the full-length AR is expressed. To date, four models have been created using the full-length expanded $\mathrm{AR}^{22-25}$ (Table 1).

One of the most important findings to emerge from the analyses of full-length AR-transgenic mice is an understanding of the role of testosterone in the pathogenic process of KD. Direct evidence for this role came from experiments in which the surgical castration of presymptomatic male mice completely eliminated the development of disease. ${ }^{23}$ Moreover, administration of testosterone to female transgenic mice elicited disease comparable to that observed in intact males. In the absence of exogenous testosterone, female mice developed mild symptoms at a later age than their male counterparts, an observation noted in other full-length AR models as well. ${ }^{22,24,25}$ Confirmation of the role of testosterone came from complementary studies carried out by Chevalier-Larsen et al. ${ }^{25}$ in which aged symptomatic male transgenic mice were subjected to surgical castration. Although motor function did not reach the level of nontransgenic littermates during the 4- to 5-month period after castration, substantial motor improvement resulted, indicating that neurons subjected to the hormone-dependent ill effects of mutant AR could recover substantial 
function in the absence of testosterone. Of note was the finding that the removal of testosterone decreased steady state levels of the mutant protein, ${ }^{25}$ and particularly decreased nuclear monomeric and aggregated protein, ${ }^{23}$ suggesting that both the increased turnover of nonliganded $\mathrm{AR}^{26}$ and/or the partial retention of mutant AR in the cytoplasm may contribute to the prevention or recovery of symptoms.

\section{TRANSCRIPTIONAL CHANGES IN KD MICE}

Transgenic models in which the mutant cDNA is expressed via the action of a heterologous promoter can provide useful insights into important features of disease pathogenesis. Moreover, such models may allow the testing of hypotheses about specific aspects of involved pathogenic pathways as well as features of the mutant protein (e.g., trafficking, post-translational modifications, etc.) necessary for disease. Such models, however, will not precisely reproduce the patterns and levels of the endogenous gene expression. Models in which the expanded repeat is "knocked in" to the endogenous gene via homologous recombination, or in which the gene is expressed via heterologous YAC transgenesis yield animals in which the expression patterns and levels will exactly mimic or closely recapitulate, respectively, the endogenous gene expression. Such a YAC transgenic model was recently described, ${ }^{24}$ in which the expression patterns and levels closely recapitulate those of endogenous AR. Indeed, this model nicely reproduces the specific lower motor phenotype of KD patients.

Several studies have implicated transcriptional dysregulation as a pathogenic mechanism at work in polyglutamine disease. ${ }^{27-32}$ Insights into one potential mechanism came from the observation that the transcriptional coactivator CBP [CAMP response element binding protein-binding protein] is reduced in effective amount by either sequestration into $\mathrm{NII}^{27,29}$ or enhanced degradation in non-NII-containing cells. ${ }^{33}$ The implication of a CBP-based mechanism for at least some aspects of transcriptional dysregulation is particularly intriguing, given the role of CBP in the expression of vascular endothelial growth factor (VEGF), ${ }^{34-36}$ a trophic factor with a demonstrated role in motor neuron viability. ${ }^{37}$ These findings suggested a model of disease in which the polyglutamine-dependent reduction in CBP results in decreased VEGF production. Indeed, Sopher et al. ${ }^{24}$ observed decreases in one isoform of VEGF concomitant with increased CBP/AR interaction at an early, presymptomatic age, suggesting that this pathological feature may represent a causative pathway in KD. This finding has important implications for potential therapeutic avenues.

\section{NEURONAL DEATH: TO DIE OR NOT TO DIE?}

Transgenic mouse models expressing either truncated or expanded $\mathrm{AR}^{20}$ or an isolated long glutamine tract $\mathrm{t}^{21}$ developed neurologic symptoms in the absence of neuron loss. These findings suggest that this pathological characteristic may occur very late in disease progression and be therefore inconsequential to the early symptoms of KD. Neuronal cell death may also require the expression and metabolism of the full-length mutant protein. The data from the various full-length mouse models are somewhat conflicting on this point (Table 1), although some common features have been observed. For example, the analysis of PrP promoter-AR112 transgenic mice described by Chevalier-Larsen et al. ${ }^{25}$ revealed no loss of neurons from the brain or spinal cord, although quantitative analysis was confined to the spinal cord. Moreover, no signs of neurogenic muscle atrophy were observed. Nonetheless, signs of pathology with regard to the formation of NII and the substantial decrease in the immunostaining of unphosphorylated neurofilament heavy chain (NF-H) in motor neuron soma were evident. ${ }^{25}$ In keeping with these findings, Katsuno et al. ${ }^{23}$ observed little or no neuronal loss in their transgenic mice expressing a full-length AR bearing 97 CAG repeats under the control of the chicken $\beta$-actin promoter. Despite the absence of a quantitative loss, a characteristic sign of neurogenic muscle atrophy, fiber type grouping, was present in these mice. In addition, analysis of ventral roots at the level of the lumber spinal cord revealed a decrease in diameter of the largest caliber axons. Lastly, whereas motor neuron number was not significantly altered, the size of the motor neuron soma was reduced. A similar observation of neurogenic muscle atrophy was observed in the YAC transgenic mice described by Sopher et al. ${ }^{24}$; in addition, motor neuron number was described as reduced, although a quantitative analysis was not described. At the other extreme of this neuropathological spectrum are the findings of McManamny et al. $^{22}$ in which both motor neuron loss and neurogenic muscle atrophy were observed in transgenic mice expressing a full-length AR bearing 120 CAGs under the expression of the cytomegalovirus (CMV) promoter. From these studies, it is yet unclear as to the underlying basis of the neuronal cell death that occurs in some transgenic models but not others. Nonetheless, the finding that progressive neurologic disease can occur in some of these full-length AR models in the absence of cell death indicates that expression of the full-length AR transgene is not sufficient to produce motor neuron loss. It is notable that the mice described by Katsuno et al. ${ }^{23}$ develop signs of neurogenic muscle atrophy, even in the absence of motor neuron loss. This finding, combined with the observation of reduced myelinated fiber size, 
suggests an axonal dysfunction resulting in abnormal muscle innervation. In addition, the lack of either neuronal loss or muscle pathology in the mice of ChevalierLarsen et al. ${ }^{25}$ supports the idea that the neurologic phenotypes observed result from neuronal dysfunction rather than neuronal loss.

\section{NII IN KD MODELS}

A common pathological feature found in nearly all polyglutamine diseases is the observation of NII. These intranuclear accumulations have been observed in autopsy material of KD patients, as well as in various cell and animal models of KD (Table 1). A characteristic hallmark of the nuclear inclusions of KD is the exclusive finding of amino-terminal epitopes within $\mathrm{NII}^{3}$ (FIG. 1). In KD autopsy material, NII were observed at a low frequency in remaining spinal motor neurons and at a reduced frequency in nonneural tissues. ${ }^{4}$ In transgenic mouse models of disease, not all models exhibited this pathologic feature. Notably, the CMV promoter AR120 mice of McManamny et al. ${ }^{22}$ and the YAC AR100 mice of Sopher et al. ${ }^{24}$ did not exhibit NII. Although YAC AR100 mice did not exhibit NII, they did show signs of accumulated nuclear AR protein, as did the actin promoter AR97 mice of Katsuno et al. ${ }^{23}$ Both the actinAR97 transgenic mice and the PrP-AR112 transgenic mice developed NII. The NII of Chevalier-Larsen et al. ${ }^{25}$ exhibited epitopes nearly identical to NII of patient studies, ${ }^{3}$ being detected by antibodies to amino-terminal epitopes. Several lines of evidence have suggested that the presence of NII is not coupled to toxicity. ${ }^{38-39 a}$ More recently a strong dissociation of NII with toxicity was described. ${ }^{40}$ These findings suggest a hypothesis that posits the coupling of NII with protection from neuronal cell death. ${ }^{40}$ It may be that the presence of NII in PrPand actin-promoter transgenic models ${ }^{23,25}$ serves to prevent the death of these neurons. However, the lack of neuronal cell death of non-NII-containing neurons indicates that determination of the survival of neurons is substantially more complex than the simple presence or absence of NII. The possibility that cellular dysfunction and/or death is linked to the nuclear accumulation of diffuse AR is suggested by the correlation of diffuse nuclear AR with disease state in the presence and absence of testosterone. ${ }^{23}$ Whether pathology is linked to the presence of a specific toxic conformer of mutant $\mathrm{AR}^{41}$ awaits further studies.

\section{OTHER PATHOLOGICAL FEATURES IN KD MODELS}

Alterations in neurofilament structure and phosphorylation have been implicated in other neurodegenerative diseases, including ALS. ${ }^{42}$ In ALS, the hyperphospho- rylation of NF-H likely leads to its proximal axonal accumulation; however, whether this pathological feature causes or results from defects in axonal transport is unknown. ${ }^{43}$ In a KD mouse model, Chevalier-Larsen et $\mathrm{al}^{25}$ showed that the unphosphorylated form of NF-H, normally expressed at high levels in neuronal cell bodies, is significantly and substantially reduced in transgenic AR112 male mice. Moreover, the castration of aged transgenic males resulted in the restoration of unphosphorylated NF-H levels to nearly normal levels, coincident with the improvement of motor function. Further studies have revealed the concomitant increase of phosphorylated NF-H within neuronal nuclei and decreased incorporation of NF-H into filaments (Chevalier-Larsen, E., and D. E. Merry, unpublished data). How the mislocalization of phosphorylated NF-H in affected neurons and/or its depletion from axons contributes to the cellular dysfunction of this model remains to be determined, but it is tempting to speculate that cytoskeletal organization may contribute to neuronal dysfunction in KD.

\section{UNDERSTANDING THE ROLE OF AR METABOLISM THROUGH DROSOPHILA MODELS OF KD}

An early Drosophila model of KD mimicked in content the truncated AR expressed in the PrP-tAR112 transgenic mice. ${ }^{20}$ Expression of truncated, expanded AR led to neural degeneration that was coupled to aggregation of the mutant protein. ${ }^{44}$ These studies illuminated a role, not only for molecular chaperones and proteasomal degradation, but also for the small ubiquitin-like modifier (SUMO) in the pathogenesis of polyglutamine disease, ${ }^{44}$ suggesting that trafficking and/or the metabolism of AR controlled by SUMO modification of other proteins impacts KD pathogenesis. In this way, Drosophila genetics was used to identify pathways of pathogenesis likely to be involved in KD.

A more recent Drosophila model, engineered to express the full-length expanded AR, not only revealed the critical role for hormone binding in the pathogenesis of $\mathrm{KD}$, but revealed important details about specific aspects of mutant AR metabolism in disease. ${ }^{45}$ Specifically, the role of the nucleus and DNA-binding functions of the AR were investigated through various genetic modifications and pharmacologic manipulations. Whereas both full-length and truncated A/B domain AR induced neurodegeneration in a ligand-dependent and -independent manner, respectively, the same proteins targeted to the cytosol by the incorporation of nuclear export signals (NES) failed to induce the pathogenic process.

The finding that hormone binding is a required element of the pathogenicity of expanded AR suggests that pharmacologic antagonists of the AR might serve a useful therapeutic purpose. Unexpectedly, treatment of flies 
expressing the full-length expanded AR with either hydroxyflutamide or biculutamide failed to protect from the neurodegenerative process and indeed exacerbated disease. These AR antagonists, while preventing AR-dependent transcription, nonetheless promoted the nuclear translocation of the AR. In similar manner, the abnormal pathology of AR nuclear aggregation was also promoted by flutamide in a cell model of KD. ${ }^{46}$ These data indicate that the transcriptional activation function of the AR is dispensable to the pathogenic process in KD and further implicate the nucleus as the primary site of pathogenesis.

\section{THERAPEUTIC AVENUES IN KD}

The most critical discovery from the variety of fulllength androgen receptor transgenic models is the knowledge that binding of the steroid hormone ligand to the mutant androgen receptor is required for initiating the disease process. Furthermore, the finding that androgen receptor antagonists also promote the disease process suggests that toxicity of the AR originates downstream of hormone binding and is independent of its function as a transcriptional activator. These data suggest that the nuclear translocation of the mutant AR is central to the disease process; indeed, the addition of a nuclear export signal to the mutant AR ameliorated its toxicity. ${ }^{45}$ Additional studies to confirm that the NES-tagged AR is retained in the cytoplasm, or that an NLS-deleted AR construct fails to cause disease, would further solidify this notion.

The finding that hormone binding is a required initiating event in the pathogenesis of $\mathrm{KD}$, that removal of hormones through surgical or chemical castration prevented disease onset ${ }^{23,47}$ and that hormone removal reversed disease symptoms in transgenic mice with progressed disease, ${ }^{25}$ suggests that hormone-based therapeutic approaches are likely to be successful in KD. Whether chemical castration via the use of the LHRH agonist leuprorelin, known to be effective in a mouse model of $\mathrm{KD}^{47}$ will prove effective in $\mathrm{KD}$ patients awaits the results of clinical trials.

Another important conclusion from the transgenic mouse models using various promoters is that, to some extent, determinants of motor neuron specificity reside within the context of the full-length AR protein. Whereas expression of the truncated form of the expanded AR, driven by the strong prion protein promoter, resulted in neurologic disease affecting many neuronal populations, ${ }^{20}$ expression of the full-length mutant AR with identical repeat length resulted in substantially restricted symptoms. ${ }^{25}$ Even at very old ages, when motor function was extremely reduced, male transgenic mice failed to exhibit the extreme tremor and handling-induced seizures found in the truncated mouse model; indeed, mice exhibited reduced limb muscle strength and reduced muscle tone, signs of lower motor neuron disease. These data suggest, therefore, that aspects of full-length AR function or metabolism may contribute to motor neuron specificity. Expression levels and patterns likely contribute as well, as substantial lower motor neuron specificity was observed in YAC100 transgenic mice, ${ }^{24}$ in which the normal expression patterns of the AR were largely recapitulated.

An appealing suggestion of a factor contributing to motor neuron specificity may come from the recent finding that spinal and brainstem motor neurons express exquisitely high levels of the testosterone-metabolizing enzyme $5 \alpha$-reductase. ${ }^{48}$ The presence of this enzyme, which reduces testosterone to the more potent androgen dihydrotestosterone, in spinal and brainstem motor neurons indicates that all testosterone in these neurons is converted to dihydrotestosterone, rather than to estrogen via aromatization. Whether KD symptoms and pathology can be ameliorated via pharmacologic inhibitors of $5 \alpha$ reductase can be tested using the current full-length AR KD mouse models.

The finding that a potent motor neuron trophic factor, VEGF, was depleted in spinal motor neurons of another transgenic model ${ }^{24}$ raises yet additional implications for a therapeutic approach. Recent studies have revealed the successful lentiviral delivery of VEGF to lower motor neurons in a mouse model of $\mathrm{ALS}^{49}$; disease symptoms were substantially delayed. Such a retrograde targeting approach may therefore be highly promising for $\mathrm{KD}$, a purely lower motor neuron disease.

The question of retrograde transport for the delivery of therapeutics in KD is an important one. Deficits in anterograde transport exist in cell models of $\mathrm{KD},{ }^{50,51}$ due to the presence of axonal accumulations of the mutant protein. Although it was previously unclear whether such aggregates occur in KD patients, the recent findings of cytoplasmic aggregates in $\mathrm{KD}^{5}$ suggest that proximal axonal aggregates may indeed be present in $\mathrm{KD}$ and may similarly impact anterograde transport. Retrograde transport is impaired in mutant HD flies, ${ }^{52}$ although genetic data indicate that this defect arises from the loss of HD function. Whether retrograde transport defects exist in $\mathrm{KD}$ remains to be determined. Strong support for the hypothesis that retrograde transport defects may contribute to motor neuron disease comes from the finding of a slowly progressing autosomal form of ALS with bulbar symptoms caused by mutation in the gene encoding a critical component of the retrograde machinery, p150glued. ${ }^{53}$ Furthermore, missense mutations in dynein heavy chain ${ }^{54}$ and the overexpression of another component of the transport machinery, dynamitin, ${ }^{55}$ resulted in defective retrograde transport and a slowly progressive lower motor neuron disease.

The suggestion that one animal model of KD may not serve all needs of the research community is clear from 
the evaluation of the various models reviewed here (Table 1). For example, the YAC transgenic model of Sopher et al. ${ }^{24}$ may represent the best genetic reproduction of KD to date. This model uses the AR promoter itself, presumably with all of its regulatory elements, ${ }^{14}$ to drive transgene expression in the same cells and with the same levels as endogenous AR. However, this model shows relatively late onset of symptoms, making it somewhat unwieldy for preclinical studies. The model of Katsuno et al. ${ }^{23}$ shows relatively early onset of disease symptoms; the disease progresses rapidly and results in death of the animals by approximately 6 months of age. These mice therefore represent a powerful model for preclinical studies, and indeed this promise has been borne out in preclinical as well as proof-of-principle therapeutic studies. ${ }^{47,56,57}$ However, the disease in these animals is irreversible very early in its progression, confining studies to presymptomatic animals. The reason for the difference in reversibility in these mice compared with the more slowly progressing disease model of ChevalierLarsen et al. ${ }^{25}$ is unclear but likely reflects differences in expression patterns and perhaps the different involvement of muscle in disease pathology. The mice of Chevalier-Larsen et al. ${ }^{25}$ show relatively early onset but slow disease progression; improvement of symptoms in substantially diseased animals may allow the testing of therapeutic applications that may reverse, rather than simply halt, disease progression. The most accurate genetic mouse model of KD is represented by one in which the mutant expanded AR sequence is knocked-in to the endogenous mouse AR locus. This model will allow the evaluation of disease driven by the AR with the exact expression pattern and levels as seen in KD patients, and in the absence of endogenous AR. Such mice have been generated and develop symptoms of $\mathrm{KD}$ as expected (Lieberman, A., personal communication). It is anticipated that the evaluation of this model will provide novel insights into pathogenic mechanisms of KD.

In summary, the development of animal models of KD that will serve the varied needs of the research community to unravel basic pathogenic pathways in KD and to test new therapeutic strategies has benefitted from the use of cDNA and YAC transgenic strategies, from the use of truncated and full-length AR molecules, and from the use of different model organisms. The future strength of the various transgenic models will be truly borne out by thorough molecular and physiologic studies using several models, to define central common pathogenic features.

Acknowledgments: I would like to thank Andrew Lieberman and Erica Chevalier-Larsen for helpful discussions and critical reading of this manuscript.

\section{REFERENCES}

1. Kennedy WR, Alter M, Sung JH. Progressive proximal spinal and bulbar muscular atrophy of late onset: a sex-linked recessive trait. Neurology 18:671-680, 1968.

2. Sobue G, Hashizume Y, Mukai E, Hirayama M, Mitsuma T, Takahashi A. X-linked recessive bulbospinal neronopathy: a clinicopathological study. Brain 112:209-232, 1989.

3. Li M, Miwa S, Kobayashi Y, Merry DE, Yamamoto M, Tanaka F, et al. Nuclear inclusions of the androgen receptor protein in spinal and bulbar muscular atrophy. Ann Neurol 44:249-254, 1998.

4. Li M, Nakagomi Y, Kobayashi Y, Merry DE, Tanaka F, Doyu M, et al. Nonneural nuclear inclusions of androgen receptor protein in spinal and bulbar muscular atrophy. Am J Pathol 153:695-701, 1998.

5. Adachi H, Katsuno M, Minamiyama M, Waza M, Sang C, Nakagomi $\mathrm{Y}$, et al. Widespread nuclear and cytoplasmic accumulation of mutant androgen receptor in SBMA patients. Brain 57:236251, 2005.

6. Ferlini A, Patrosso MC, Guidetti D, Merlini L, Uncini A, Ragno $\mathrm{M}$, et al. Androgen receptor gene (CAG)n repeat analysis in the differential diagnosis between Kennedy disease and other motoneuron disorders. Am J Med Genet 55:105-111, 1995.

7. Fischbeck KH, Ionasescu V, Ritter AW, Ionasescu R, Davies K, Ball S, et al. Localization of the gene for X-linked spinal muscular atrophy. Neurology 36:1595-1598, 1986.

8. Migeon BR, Brown TR, Axelman J, Migeon CJ. Studies of the locus for androgen receptor: localization on the human X chromosome and evidence for homology with the Tfm locus in the mouse. Proc Natl Acad Sci USA 78:6339-6343, 1981.

9. La Spada AR, Wilson EM, Lubahn DB, Harding AE, Fischbeck $\mathrm{KH}$. Androgen receptor gene mutations in X-linked spinal and bulbar muscular atrophy. Nature 353:77-79, 1991.

10. La Spada AR, Roling D, Harding AE, Warner CL, Speigel R, Hausmanowa-Petrusewicz I, et al. Meiotic stability and genotypephenotype correlation of the expanded trinucleotide repeat in Xlinked spinal and bulbar muscular atrophy. Nat Genet 2:301-304, 1992.

11. Zoghbi HY, Orr HT. Glutamine repeats and neurodegeneration. Апnи Rev Neurosci 23:217-247, 2000.

12. Bingham PM, Scott MO, Wang S, McPhaul MJ, Wilson EM, Garbern JY, et al. Stability of an expanded trinucleotide repeat in the androgen receptor gene in transgenic mice. Nat Genet 9:191196, 1995.

13. Merry DE, McCampbell A, Taye AA, Winston RL, Fischbeck KH. Toward a mouse model for spinal and bulbar muscular atrophy: effect of neuronal expression of androgen receptor in transgenic mice. Am J Hum Genet 59 [Suppl]:A271, 1996.

14. La Spada AR, Peterson KR, Meadows SA, McClain ME, Jeng G, Chmelar RS, et al. Androgen receptor YAC transgenic mice carrying CAG 45 alleles show trinucleotide repeat instability. Hum Mol Genet 7:959-967, 1998.

15. Ikeda H, Yamaguchi M, Sugai S, Aze Y, Naruiya S, Kakizuka A. Expanded polygluatmine in the Machado-Joseph disease protein induces cell death in vitro and in vivo. Nat Genet 13:196-202, 1996.

16. Paulson HL, Perez MK, Trottier Y, Trojanowski JQ, Subramony $\mathrm{SH}$, Das SS, et al. Intranuclear inclusions of expanded polyglutamine protein in spinocerebellar ataxia type 3. Neuron 19:1-20, 1997.

17. Merry DE, Kobayashi Y, Bailey CK, Taye AA, Fischbeck KH. Cleavage, aggregation and toxicity of the expanded androgen receptor in spinal and bulbar muscular atrophy. Hum Mol Genet 7:693-701, 1998.

18. Brooks BP, Paulson HL, Merry DE, Salazar-Grueso EF, Brinkmann AO, Wilson EM, et al. Characterization of an expanded glutamine repeat androgen receptor in a neuronal cell culture system. Neurobiol Dis 4:313-323, 1997.

19. Diamond MI, Robinson MR, Yamamoto KR. Regulation of expanded polyglutamine protein aggregation and nuclear localization by the glucocorticoid receptor. Proc Natl Acad Sci USA 97:657$661,2000$.

20. Abel A, Walcott J, Woods J, Duda J, Merry DE. Expression of 
expanded repeat androgen receptor produces neurologic disease in transgenic mice. Hum Mol Genet 10:107-116, 2001.

21. Adachi H, Kume A, Li M, Nakagomi Y, Niwa H, Do J, et al. Transgenic mice with an expanded CAG repeat controlled by the human AR promoter show polyglutamine nuclear inclusions and neuronal dysfunction without neuronal cell death. Hum Mol Genet 10:1039-1048, 2001

22. McManamny P, Chy HS, Finkelstein DI, Craythorn RG, Crack PJ, Kola I, et al. A mouse model of spinal and bulbar muscular atrophy. Hum Mol Genet 11:2103-2111, 2002.

23. Katsuno M, Adachi H, Kume A, Li M, Nakagomi Y, Niwa H, et al. Testosterone reduction prevents phenotypic expression in a transgenic mouse model of spinal and bulbar muscular atrophy. Neuron 35:843-854, 2002.

24. Sopher BL, Thomas PS Jr, LaFevre-Bernt MA, Holm IE, Wilke $\mathrm{SA}$, Ware CB, et al. Androgen receptor YAC transgenic mice recapitulate SBMA motor neuronopathy and implicate VEGF164 in the motor neuron degeneration. Neuron 41:687-699, 2004.

25. Chevalier-Larsen ES, O'Brien CJ, Wang H, Jenkins SC, Holder L, Lieberman AP, et al. Castration restores function and neurofilament alterations of aged symptomatic males in a transgenic mouse model of spinal and bulbar muscular atrophy. J Neurosci 24:4778 4786, 2004.

26. Zhou Z-x, Lane MV, Kamppainen JA, French FS, Wilson EM. Specificity of ligand-dependent androgen receptor stabilization: receptor domain interactions influence ligand dissociation and receptor stability. Mol Endocrinol 9:208-218, 1995.

27. Nucifora JFC, Sasaki M, Peters MF, Huang H, Cooper JK, Yamada $\mathrm{M}$, et al. Interference by huntingtin and atrophin-1 with CBP-mediated transcription leading to cellular toxicity. Science 291:2423-2428, 2001

28. Dunah AW, Jeong H, Griffin A, Kim YM, Standaert DG, Hersch SM, et al. Sp1 and TAFII130 transcriptional activity disrupted in early Huntington's disease. Science 296:2238-2243, 2002.

29. McCampbell A, Taylor JP, Taye AA, Robitschek J, Li M, Walcott $\mathrm{J}$, et al. CREB-binding protein sequestration by expanded polyglutamine. Hum Mol Genet 9:2197-2202, 2000.

30. McCampbell A, Taye AA, Whitty L, Penney E, Steffan JS, Fischbeck KH. Histone deacetylase inhibitors reduce polyglutamine toxicity. Proc Natl Acad Sci USA 98:15179-15184, 2001.

31. Steffan JS, Bodai L, Pallos J, Poelman M, McCampbell A, Apostol BL, et al. Histone deacetylase inhibitors arrest polyglutaminedependent neurodegeneration in Drosophila. Nature 413:739-743, 2001.

32. Hockly E, Richon VM, Woodman B, Smith DL, Zhou X, Rosa E, et al. Suberoylanilide hydroxamic acid, a histone deacetylase inhibitor, ameliorates motor deficits in a mouse model of Huntington's disease. Proc Natl Acad Sci USA 100:2041-2046, 2003.

33. Jiang H, Nucifora FC Jr, Ross CA, DeFranco DB. Cell death triggered by polyglutamine-expanded huntingtin in a neuronal cell line is associated with degradation of CREB-binding protein. Hum Mol Genet 12:1-12, 2003.

34. Carrero P, Okamoto K, Coumailleau P, O'Brien S, Tanaka H, Poellinger L. Redox-regulated recruitment of the transcriptional coactivators CREB-binding protein and SRC-1 to hypoxia-inducible factor $1 \alpha$. Mol Cell Biol 20:402-415, 2000.

35. Dames SA, Martinez-Yamout M, de Guzman RN, Dyson HJ, Wright PE. Structural basis for Hif-1 $\alpha / \mathrm{CBP}$ recognition in the cellular hypoxic response. Proc Natl Acad Sci USA 99:5271-5276, 2002.

36. Freedman SJ, Sun ZY, Poy F, Kung AL, Livingston DM, Wagner $\mathrm{G}$, et al. Structural basis for recruitment of CBP/p300 by hypoxiainducible factor-1 $\alpha$. Proc Natl Acad Sci USA 99:5367-5372, 2002.

37. Oosthuyse B, Moons L, Storkebaum E, Beck H, Nuyens D, Brusselmans K, et al. Deletion of the hypoxia-response element in the vascular endothelial growth factor prmoter causes motor neuron degeneration. Nat Genet 28:131-138, 2001.

38. Saudou F, Finkbeiner S, Devys D, Greenberg ME. Huntingtin acts in the nucleus to induce apoptosis but death does not correlate with the formation of intranuclear inclusions. Cell 95:55-66, 1998.

39. Klement IA, Skinner PJ, Kaytor MD, Yi H, Hersch SM, Clark HB, et al. Ataxin-1 nuclear localization and aggregation: role in poly- glutamine-induced disease in SCA1 transgenic mice. Cell 95:4153, 1998.

39a. Simeoni S, Mancini MA, Stenoien DL, Marcelli M, Weigel NL, Zanisi M, Martini L, Poletti A. Motoneuronal cell death is not correlated with aggregate formation of androgen receptors containing an elongated polyglutamine tract. Hum Mol Genet 9:133$144,2000$.

40. Arrasate M, Mitra S, Schweitzer ES, Segal MR, Finkbeiner S Inclusion body formation reduces levels of mutant huntingtin and the risk of neuronal death. Nature 431:805-810, 2004.

41. Wacker JL, Zareie MH, Fong H, Sarikaya M, Muchowski PJ. Hsp70 and Hsp40 attenuate formation of spherical and annular polyglutamine oligomers by partitioning monomer. Nat Struct Mol Biol 11:1215-1222, 2004.

42. Hirano A, Donnenfeld H, Sasaki S, Nakano I. Fine structural observations of neurofilamentous changes in amyotrophic lateral sclerosis. J Neuropathol Exp Neurol 43:461-470, 1984.

43. Holzbaur ELF. Motor neurons rely on motor proteins. Trends Cell Biol 14:233-240, 2004.

44. Chan HY, Warrick JM, Andriola I, Merry D, Bonini NM. Genetic modulation of polyglutamine toxicity by protein conjugation pathways in Drosophila. Hum Mol Genet 11:2895-2904, 2002.

45. Takeyama K, Ito S, Yamamoto A, Tanimoto H, Furutani $T$, Kanuka $\mathrm{H}$, et al. Androgen-dependent neurodegeneration by polyglutamine-expanded human androgen receptor in Drosophila. Neuron 35:855-864, 2002.

46. Walcott JL, Merry DE. Ligand promotes intranuclear inclusions in a novel cell model of spinal and bulbar muscular atrophy. J Biol Chem 277:50855-50859, 2002.

47. Katsuno M, Adachi H, Doyu M, Minamiyama M, Sang C, Kobayashi $\mathrm{Y}$, et al. Leuprorelin rescues polyglutamine-dependent phenotypes in a transgenic mouse model of spinal and bulbar muscular atrophy. Nat Med 9:768-773, 2003.

48. Pozzi P, Bendotti C, Simeoni S, Piccioni F, Guerini V, Marron $\mathrm{TU}$, et al. Androgen 5- $\alpha$-reductase type 2 is highly expressed and active in rat spinal cord motor neurones. $J$ Neuroendocrinol 15 : 882-887, 2003.

49. Azzouz M, Ralph GS, Storkebaum E, Walmsley LE, Mitrophanous KA, Kingsman SM, et al. VEGF delivery with retrogradely transported lentivector prolongs survival in a mouse ALS model. Nature 429:413-417, 2004.

50. Szebenyi G, Morfini GA, Babcock A, Gould M, Selkoe K, Stenoien DL, et al. Neuropathogenic forms of huntingtin and androgen receptor inhibit fast axonal transport. Neuron 40:41-52, 2003.

51. Piccioni F, Pinton P, Simeoni S, Pozzi P, Fascio U, Vismara G, et al. Androgen receptor with elongated polyglutamine tract forms aggregates that alter axonal trafficking and mitochondrial distribution in motor neuronal processes. FASEB $J$ 16:14181420, 2002.

52. Gunawardena S, Her L-S, Brusch RG, Laymon RA, Niesman IR, Gordesky-Gold B, et al. Disruption of axonal transport by loss of huntingtin or expression of pathogenic polyQ proteins in Drosophila. Neuron 40:25-40, 2003.

53. Puls I, Jonnakuty C, LaMonte BH, Holzbaur EL, Tokito M, Mann $\mathrm{E}$, et al. Mutant dynactin in motor neuron disease. Nat Genet 33:455-456, 2003

54. Hafezparast M, Klocke R, Ruhrberg C, Marquardt A, AhmadAnnuar A, Bowen S, et al. Mutations in dynein link motor neuron degeneration to defects in retrograde transport. Science 300:808 $812,2003$.

55. LaMonte BH, Wallace KE, Holloway BA, Shelly SS, Ascano J, Tokito M, et al. Disruption of dynein/dynactin inhibits axonal transport in motor neurons causing late-onset progressive degeneration. Neuron 34:715-727, 2002.

56. Minamiyama M, Katsuno M, Adachi H, Waza M, Sang C, Kobayashi $\mathrm{Y}$, et al. Sodium butyrate ameliorates phenotypic expression in a transgenic mouse model of spinal and bulbar muscular atrophy. Hum Mol Genet 13:1183-1192, 2004.

57. Adachi H, Katsuno M, Minamiyama M, Sang C, Pagoulatos G, Angelidis C, et al. Heat shock protein 70 chaperone overexpression ameliorates phenotypes of the spinal and bulbar muscular atrophy transgenic mouse model by reducing nuclear-localized mutant androgen receptor protein. $J$ Neurosci 23:2203-2211, 2003. 